\title{
Brain electromagnetic activity and lightning: potentially congruent scale-invariant quantitative properties
}

\author{
Michael A. Persinger ${ }^{1,2}$ * \\ ${ }^{1}$ Behavioural Neuroscience Program, Department of Psychology, Laurentian University, Sudbury, ON, Canada \\ ${ }^{2}$ Biomolecular Sciences Program, Department of Biology, Laurentian University, Sudbury, ON, Canada
}

\section{Edited by:}

Sidney A. Simon, Duke University,

USA

\section{Reviewed by:}

Antonio Pereira, Federal University of Rio Grande do Norte, Brazil

Adrian Rodriguez-Contreras, City

College of New York, USA

\section{${ }^{*}$ Correspondence:}

Michael A. Persinger, Behavioural Neuroscience Program, Department of Psychology, Laurentian University,

Sudbury, ON, Canada P3E 2C6.

e-mail: mpersinger@laurentian.ca
The space-time characteristics of the axonal action potential are remarkably similar to the scaled equivalents of lightning. The energy and current densities from these transients within their respective volumes or cross-sectional areas are the same order of magnitude. Length-velocity ratios and temporal durations are nearly identical. There are similar chemical consequences such as the production of nitric oxide. Careful, quantitative examination of the characteristics of lightning may reveal analogous features of the action potential that could lead to a more accurate understanding of these powerful correlates of neurocognitive processes.

Keywords: lightning, action potentials, current density, resonance, natural patterns, nitric oxide

\section{INTRODUCTION}

That information is propagated as sequential series of digital signals along distinct paths whose lengths are much longer than their widths is a primary assumption of contemporary neuronal function. Dispersion rates are within the range of $1-100 \mathrm{~m} / \mathrm{s}$ with space constants in the order of about $1 \mathrm{~mm}$. The fastest of these transients exhibit saltatory movements between specialized conductive spaces along the axon barrels. The ratios and scaling of the spatial and temporal relationships of these mediators of the "language of the brain" share remarkable similarities to lightning. Because lightning's absolute spatial scale is so large compared to the observer's reference point, minute characteristics are discerned whose equivalence at the level of the axon are below contemporary resolution. Quantitative identities between these two classes of phenomena could encourage alternative interpretations of the electromagnetic (EM) components of action potentials and reveal recondite relationships concerning neuronal function.

The identity between exogenous and endogenous "electricity" is not really a new idea. The observation that atmospheric electricity, lightning, and the electrical fields within living systems, "nerve conduction," shared similar origins was considered as early as the 18th century by Galvani and Volta. Galvani showed contractions in frog muscles elicited from Leyden jars and electric machines was the same as those evoked during lightning when a long metallic wire was connected to the crural nerves and pointed to the sky (Piccolino, 1997). The similarity has been viewed historically as more of a congruence of quality than a potential blueprint for quantitative characteristics. In the present comparison these features are demonstrated. To facilitate understanding the calculations and reasoning for the similarities between action potentials and lightning will be articulated in greater detail than the usual narrative discussion in the neurosciences.

The concept of scale-invariance or recurrent ratios (Kolombet, 1996) within measurements of the physical world assumes an intrinsic repeated structure within the varying increments of space $(\Delta s)$ and time $(\Delta t)$ as well as their relationships (Persinger, 1999). For example the proportion of matter (protons and electrons) that occupies the space (volume) occupied by an atom is about 1 part per trillion. The ratios of the volume of the sun and planets within the space of the solar system and the stars within galactic space are the same order of magnitude.

One temporal example is the equivalent order of magnitude of the ratio of the electron orbital time of a hydrogen atom to its precession and the earth's rotation to its spin axis gyration. Comparable "scale-invariance" has been found within the human brain (Persinger and Lavallee, 2010, 2012) and for functional EM fields within the cerebrum and over very large spaces (Persinger, 2008, 2011; Persinger et al., 2008). The concept is similar to that described as gnomons (Gazalé, 1999) and fractals. A gnomon is "that form that, when added to some form, results in a new form similar to the original".

\section{ENERGY DENSITIES IN THE HUMAN BRAIN AND THE ATMOSPHERE}

Action potentials are the carriers of the discrete signals along the axon barrel. An average net potential difference for an action potential $(-70$ to $+50 \mathrm{mV})$ is $1.2 \times 10^{-1} \mathrm{~V}$ which would exert on each unit charge of $1.6 \times 10^{-19}$ Coulomb (A.s) an energy of $1.9 \times 10^{-20} \mathrm{~J}$ (Wei, 1969). If we assume $\sim 10^{10}$ neurons occupy human cerebral cortices (Blinkov and Glezer, 1968) with an average frequency of propagation of $1 \mathrm{~Hz}$, the total energy per second involved with just the effects of all action potentials within brain space would be about $10^{-10} \mathrm{~J} / \mathrm{s}$. The volume $(\sim 1330 \mathrm{cc})$ of an average brain is $1.3 \times 10^{-3} \mathrm{~m}^{3}$. This results in an energy density of about $10^{-7} \mathrm{~J} / \mathrm{s} \cdot \mathrm{m}^{3}$ (Persinger, 2010).

On the other hand the typical lightning stroke involves a flow of $\sim 10$ Coulomb (C) of electrons across a potential difference of $10^{8} \mathrm{~V}$ resulting in $10^{9} \mathrm{~J}$ (Ogawa, 1982). There are about 
70-100 lightning flashes/s world wide (Israel, 1973; Rennie, 1999) resulting in (assuming 100 flashes) the generation of $10^{11} \mathrm{~J} / \mathrm{s}$ or 100 Gigawatts of power. For reference there is $4.3 \times 10^{12} \mathrm{~J}$ per kiloton (kT) of standard explosives such that the energy generated every approximately $14 \mathrm{~min}$ by global electrical discharges is equivalent to about a $20 \mathrm{kT}$ (Hiroshima-like) nuclear explosion.

Most of this energy from lightning discharges is within a narrow shell of about $2 \mathrm{~km}$ within the biosphere. The volume of this shell, assuming a radius of $6,378 \mathrm{~km}$ for the earth, would be about $1 \times 10^{18} \mathrm{~m}^{3}$. This means the energy density would be $10^{11} \mathrm{~J} / \mathrm{s} \cdot 10^{18} \mathrm{~m}^{3}$ or $10^{-7} \mathrm{~J} / \mathrm{s} \cdot \mathrm{m}^{3}\left(10^{-7} \mathrm{~W} / \mathrm{m}^{3}\right)$. This energy density is remarkably similar to that generated by action potentials within the brain. When applied across the 3-5 mm thickness of the cerebral cortices, the value is equivalent to $10^{-10} \mathrm{~W} / \mathrm{m}^{2}$ which is within the range of power of photon emissions near the skull when subjects engage in specific imagination (Dotta et al., 2011; Dotta and Persinger, 2011) and which is strongly correlated with the power of electroencephalographic (EEG) activity (Dotta et al., 2012).

\section{COMPARABLE SCALED CURRENT DENSITIES}

About $5 \mathrm{C}$ is distributed within a lightning channel with an average current of $100 \mathrm{~A}$. Although the width of a leader channel is about $1 \mathrm{~m}$ the current flows through a channel with a radius of about $1 \mathrm{~cm}$ (Chang and Grossman, 1996). With this crosssectional area the density is $10 \times 10^{1}$ A divided by $3.14 \times 10^{-4} \mathrm{~m}^{2}$ or $3.2 \times 10^{5} \mathrm{~A} / \mathrm{m}^{2}$.

A reasonable radius for an axon is $1 \mu \mathrm{m}$. However the actual locations of the major movements of ions that affect the transmission of EM field-mediated information along the axon are within the membrane which is about $10 \mathrm{~nm}$ in width. The cross-sectional area of this small annulus around the axon would be $2 \times 10^{-14} \mathrm{~m}^{2}$. Given the average current of $10^{-9}$ A (from the approximately $10^{3}$ ion channels each with $1 \mathrm{pA}$ capacities around the ring or circumference of the axon), this would mean that the cross-sectional current "density" would be $\sim 10^{5} \mathrm{~A} / \mathrm{m}^{2}$.

Consequently even though the current is much larger in a lightning stroke because of its absolute size by a factor of $10^{10}$, the "minuscule" axon potential current is comparable per crosssectional area. The range in the widths of normal axons would affect the coefficients rather than the order of magnitude. It may also be relevant that the actual charge and current per lightning stroke also displays a comparable range in the coefficient of variation. Such a large relative magnitude of potential across neuronal membranes is not a new concept. For example, the $90 \mathrm{mV}$ potential difference across a $10 \mathrm{~nm}$ membrane is equivalent to $9 \times 10^{7} \mathrm{~V} / \mathrm{m}$.

\section{SHARED "SALTATORY" CONDUCTION AND PULSE PATTERNS}

Most lightning (90\%) is between clouds. The leader moves in discrete jumps of $50 \mathrm{~m}$ at about $1.2 \times 10^{5} \mathrm{~m} / \mathrm{s}$ to $1.5 \times 10^{5} \mathrm{~m} / \mathrm{s}$. This conspicuous "saltatory" conduction of lightening has a ratio of $\left[1.2 \times 10^{5} \mathrm{~m} / \mathrm{s}\right] / 50 \mathrm{~m}$ or $2.4 \times 10^{3} \mathrm{~Hz}$ (about $2 \mathrm{kHz}$ or $0.5 \mathrm{~ms}$ ) which is remarkably similar to the absolute refractory period of the action potential. In comparison the action potential moves along the myelinated axon in discrete steps of $1 \mathrm{~mm}$ compared to the approximately $2 \mu \mathrm{m}$ width of the nodes of Ranvier.
The wave shape characteristics of action potentials and lightning flashes are similar. Villanueva et al. (1994) found all lightning pulses were the same polarity; most were single peak but about one-third were multiple-peaked. Although the mean width of the initial peak was $25 \mu \mathrm{s}$ (SD $13 \mu \mathrm{s}$ ), the ratio of the overshoot duration to the initial peak was 5.7 (SD 2.1). This ratio is within the range of the typical relative refractory to absolute refractory period in the average axon. More recent measurements of artificially triggered lightening (Zhang etal., 2009) revealed comparable peak widths. Interestingly, the initial-stage discharge time was about $20 \mathrm{~ms}$ and the time between strokes ranged from 18 to $210 \mathrm{~ms}$ (mean $87 \mathrm{~ms}$ ). This interval is within the range of the global rostral-caudal propagating, coherent waves over the cerebral cortices and the microstates that determine a percept and consciousness (Llinas and Ribary, 1993; Koenig et al., 2002).

\section{SIMILAR MASS-CHARGE VELOCITY RATIOS}

Although the velocity of a leader exceeds the $10 \mathrm{~m} / \mathrm{s}$ values exhibited by non-myelinated axons by a factor of $1.2-1.5 \times 10^{4}$, the scaled values for the mass mediating the movements of charges are similar. For example, the mass of $\mathrm{Na}+$, the major mediator of the action potential, is 30 Daltons or $48 \times 10^{-27} \mathrm{~kg}$ while the mass of an electron is $9.8 \times 10^{-31} \mathrm{~kg}$. The difference is in the order of $10^{4}$. The coefficients converge more closely when the range of hydration states (accompanying $\mathrm{H}_{2} \mathrm{O}$ molecules) associated with the ions are included.

\section{INTERFACE TIMES: STROKE-GROUND vs AXON-DENDRITE}

As the leader approaches to about $10 \mathrm{~m}$ above the ground it creates an electric field sufficient to initiate discharges rising from the ground (streams). When contact is made between the upward and downward fields a heavy surge of current occurs within 1-5 ms. This surge produces the luminosity that progresses up the path produced by the step leader at $\sim 10^{8} \mathrm{~m} / \mathrm{s}$. About 40-50 ms after the return stroke, another region of luminosity, about $50 \mathrm{~m}$ long, moves from the cloud to the ground (dart leader). It does not fork or branch. There is an average of three to four strokes with a maximum around 20 (Israel, 1973; Ogawa, 1982).

The approximately $10 \mathrm{~m}$ interface or boundary where the exchange of energy between the atmosphere and ground occurs is about $3 \times 10^{-3}$ the length of the pathway. For cortical axons with lengths between 1 and $5 \mathrm{~mm}$, this would be equivalent to a length of between 3 and $15 \mu \mathrm{m}$ which is within the range of the length of the terminal endings or boutons within which the digital information of the action potential is transformed to chemical equivalents.

The surge of current lasting for $1-5 \mathrm{~ms}$ is within the range of the time involved with release of the contents of the synaptic vesicles (Clements, 1996). The energy transfer mediated by the mass of molecules released from the vesicles into the synaptic space would be analogous to this relatively large increment of current. The occurrences of subsequent surges from the cloud to the ground after an interval of $40-50 \mathrm{~ms}$ or about 20 times after the first surge is comparable to the first and second surges of vesicular releases (Clements, 1996). 


\section{EMERGENCE OF AGGREGATE PROPERTIES}

The billions of action potentials and their correlates per second within the cerebral cortices generate emergent phenomena inferred by EEG measurements that include microstates (Koenig et al., 2002) and transient coherence of activity (Lehmann et al., 1998; Burkitt et al., 2000) over areas (tens of $\mathrm{mm}^{2}$ to tens of $\mathrm{cm}^{2}$ ) of the human brain's cortical surface. Between the earth's surface and the lower ionosphere there is a shell of optimum conduction within which the results of focal energies in one area are generated throughout the volume. Cloud-to-ground lightning discharges from global thunderstorm activity are the main excitation sources within the earth-ionospheric cavity. These omnipresent pulses propagate for megameters (Persinger et al., 1973) without appreciable attenuation and behave as a "cortical manifold" for distributing tissue-level energies (Schienle et al., 1997, 1998; Durand-Manterola et al., 2001) throughout the biosphere. The observation by Houwelling and Brecht (2008) that the activity of only one axon affected the direction of a rat's gross responding predicted that such singular neuronal "discharges" could affect the state of the entire cerebral cortical manifold (Li et al., 2009).

The fundamental frequency $(1 / \mathrm{s}=\mathrm{Hz})$ is the velocity divided by the circumference. Assuming the speed of light of $3 \times 10^{8} \mathrm{~m} / \mathrm{s}$ and the circumference of the earth as $40,000 \mathrm{~km}\left(4 \times 10^{7} \mathrm{~m}\right)$ the natural frequency is $7.8 \mathrm{~Hz}$. Harmonics for this values, often described as the Schumann resonances (Cherry, 2002), can be obtained by taking the square root of $[(n(n+1)) / 2]$ multiplied by the base frequency $(7.8 \mathrm{~Hz})$, where $n$ is the progressive series of integers $1,2,3, \ldots$, etc. Those that have been measured have peaks around 8, 14, 20, and $26 \mathrm{~Hz}$ (Campbell, 1967).

As described by Nunez (1995) in his classic chapter on "Towards a physics of the neocortex," comparable solutions exist for the human brain. The probability density function for myelinated cortico-cortical propagation peaks at about 6-9 $\mathrm{m} / \mathrm{s}$ with the halfwidth of the distribution is estimated to be between 3 and $4.5 \mathrm{~m} / \mathrm{s}$. Published estimates of the neocortical surface areas range from 1,600 to $4,000 \mathrm{~cm}^{2}$. The effective cortical radius after flat-mapping is between 11 and $18 \mathrm{~cm}$. As a result the non-dispersive brain waves from mode $n=1$ would be between 7 and $18 \mathrm{~Hz}$. Subtle shifts in peak power in this frequency vary with head size, defined by the cube root of the product of three linear measures (Nunez, 1995). As the size increased over a normal range of volunteers the peak frequency decreased from 10.6 to $9.8 \mathrm{~Hz}$.

\section{RESISTANCE-CAPACITANCE AND TIME CONSTANTS}

The EM signals associated with lightning are propagated through a medium. The simplest calculation of a time constant is the product of the resistance (in Ohms) and capacitance in Farads $(\mathrm{F})$. For free space resistance is $3.70 \times 10^{2} \mathrm{Ohms}\left[\left(\mathrm{kg} \cdot \mathrm{m}^{2}\right) /\left(\mathrm{A}^{2} \cdot \mathrm{s}^{3}\right)\right]$ and capacitance is $8.8 \times 10^{-12} \mathrm{~F} / \mathrm{m}\left[\left(\mathrm{A}^{2} \cdot \mathrm{s}^{4}\right) /\left(\mathrm{kg} \cdot \mathrm{m}^{2}\right)\right] / \mathrm{m}$ or $32.56 \times 10^{-10}$ $\mathrm{S} / \mathrm{m}$. When multiplied by the circumference of the earth, the time constant is $130 \mathrm{~ms}$ or about $7.7 \mathrm{~Hz}$; this is within the natural variation of the fundamental Schumann resonance.

Cerebral tissue is also a medium. The permeability (inductance/m) of cortical gray matter at $1 \mathrm{kHz}$ is about $10^{-2}$ Henrys, while the permittivity of gray matter is $2 \times 10^{-1} \mathrm{~F} / \mathrm{m}$ (Tsang et al., 2004). Application of the formula $f=1 /\left(2 \pi(\mathrm{LC})^{-1 / 2}\right)$, the equation for resonance frequency of a closed circuit, results in a value of about $7 \mathrm{~Hz}$. The convergence of a fundamental cerebral resonance with the Schumann solutions indicates that higher order harmonics may exist within EM fields within cerebral space and be associated with specific functions. There are often strong correlations between fluctuations in power values measured by quantitative EEG across traditional frequency bands. That resonance could occur between fields within cerebral volumes and the Schumann phenomena may have significant implications for the biosciences (Cherry, 2002; Persinger, 2008).

\section{SIMILARITY OF "AVERAGED" WAVE PATTERNS OVER SPACE}

The classical although arbitrary division of EEG activity into delta, theta, alpha, and beta activity with a myriad of complexes and transients have been considered both emergent and reflective of "distant" fields of neuronal activity. As shown by Koenig et al. (1981) all of the fundamental frequencies and patterns of EEG activity are measured within the Schumann (earth-ionospheric) cavity or as local electric field configurations during thunderstorms. In addition, biofrequency $(1-100 \mathrm{~Hz})$ pulses of about $0.5 \mathrm{~ms}$ whose carrier frequencies diminish from $100 \mathrm{kHz}$ to about $10 \mathrm{kHz}$ at distances more than $1000 \mathrm{~km}$ (Schienle et al., 1998) from the source display magnitudes in the nanoTesla $(\mathrm{nT})$ to picoTesla (pT) range (Durand-Manterola et al., 2001).

\section{SAME ORDER OF MAGNITUDES OF OPERATING INTENSITIES}

Within the range of $7-40 \mathrm{~Hz}$ the electric field components associated with the EM fields generated through the ionospheric-earth cavity are about a $\mathrm{mV} / \mathrm{m}$, while the magnetic field components are between 1 and 10 pT (Koenig et al., 1981). For comparison the magnetic field intensities within galaxies are in the order of $10^{-10} \mathrm{~T}$ with upper limits of $10^{-13} \mathrm{~T}$ for extragalactic fields (Persinger, 2011). In a manner similar to the changing, averaged power outputs of neuronal activity within the cerebral volume that can vary in response to fluctuations in subtle external energy, the Schumann values also display discrete alterations.

The long-term averages for the Schumann frequency, damping, and amplitude change as a function of solar proton events (SPE). They increase the Schumann resonance frequency from a reference value of $\sim 7.8 \mathrm{~Hz}$ by between 0.04 and $0.14 \mathrm{~Hz}$ depending upon the intensity of the proton flux. The amplitude of the resonance increased by several $10 \%$ from a mean value of about $1.0 \mathrm{pT}$ (Schlegel and Fullekrug, 1999). Electric fields within the $\mathrm{mV} / \mathrm{m}$ range and magnetic fields within the $\mathrm{pT}$ range also define the operating intensities overly spatially distributed cerebral functions (Persinger et al., 2008; Persinger and Lavallee, 2010, 2012). The strong correlations between variable power densities within the ionosphere-earth cavity and power changes within quantitative EEG measures (Mulligan et al., 2010) as well as the quantum-like properties of interhemispheric interactions (Persinger et al., 2008) indicate that physical connectivity may be pervasive.

\section{CONGRUENT PHASE MODULATIONS}

Phase modulation has been considered the most optimal means to propagate the most information over distance. Phase shift can be obtained by time divided by the square root of $\mathrm{v}^{2} / \mathrm{c}^{2}$. Because the EM fields associated with lightening generated within the 
earth-ionospheric cavity are within the $10-100 \mathrm{kHz}$ ("atmospherics" or "sferics") range, the $\Delta c / c$ (c, velocity of light) is 0.05 for this range (Tu et al., 2005). This means that the phase shift for every $1 \mathrm{~s}$ is $1 / 0.9897 \mathrm{~s}$ or $16 \mathrm{~ms}$. This magnitude of phase shift is remarkably similar to phase comparisons associated with the presence of the continuous " $40 \mathrm{~Hz}$-oscillations" over the entire cerebral cortical mantle. An approximately $12 \mathrm{~ms}$ phase shift between the rostral and caudal pole of the brain has been reported (Llinas and Pare, 1991; Llinas and Ribary, 1993).

\section{POSSIBLE NEUROSCIENCE-RELEVANT PHENOMENA RETURN STROKE AND BACKPROPAGATION}

A search for the "missing" equivalents between lightning and action potentials could be revealing in a manner similar to the search for Mendeleyev's missing elements in the Periodic Table. There is no traditional equivalent of the "return stroke" at the synapse, although backpropagation might be considered a conceptual candidate (Golding et al., 1999). However, backpropagation influences the dendrites of the neuron from which the action potential has been propagated. Its variable effect depends upon the extent by which the neuron's action potential penetrates into its own distal dendrites.

When a stepped leader approaches within a few tens of meters above the ground, it is met by a positively charged return stroke towards the cloud. Within a synaptic scenario, this would be equivalent to a "return field" transiently generated from the postsynaptic region towards the presynaptic membrane just before the arrival of the action potential. If the quantitative scale-invariant relationships between lightning and action potentials can be generalized in this context, then impulse magnetic flux densities (Rai and Bhattacharya, 1971) from the post-synaptic membrane must emerge and cross the synapse into the presynaptic membrane during the few milliseconds before the helical EM field (the action potential) reaches the synapse. In other words, a comparison with lightning would predict that sub-threshold, electrotonic-like shifts in voltage (approximately the Landauer principle limit: $\ln 2 \mathrm{kT}$, or about $10^{-21} \mathrm{~J}$ ) should be apparent at the synapse in advance of the arrival of the major action potential.

It is more likely we have not measured this equivalent rather than a frank deviation from Newton's third law: for every force there is an equal and opposite force. It is well known the repolarization of the (heart) atria after its depolarization (P) during electrocardiographic measurements is masked by the QRS component of the massive depolarization of the ventricles. The "occlusion" of the independent $\mathrm{K}+$ and $\mathrm{Na}+$ current profiles during the measurement of the spike would be another conspicuous example.

\section{NITRIC OXIDE PRODUCTION}

One class of candidates for the equivalent of the "return stroke" might be mediated by the post-synaptic release of nitric oxide (NO) or the quantal energies associated with its presence. The ionization energies of $\mathrm{N}$ and $\mathrm{O}$ differ by $0.92 \mathrm{eV}$ (electron volt) and would require an addition for "equivalence" (such as for hydrogen and oxygen) of about $2 \times 10^{-20} \mathrm{~J}$ which would be available with the voltage changes associated with an action potential (Persinger, 2010). Such charge carriers moving toward the origin (presynaptic space) could modulate presynaptic changes initiated by the source or subsequent action potential. Even the presence and functions of Hyden intersynaptic filaments, which deviate significantly from Cajal's law of neuronal independence, might be viewed from a different perspective as contributing to the "return stroke" or backpropagation.

Nitric oxide, which was once known as "endothelium-derived relaxing factor," is an important gas which diffuses freely across membranes concomitant with neurotransmission (Zweier et al., 1999) and has been considered a means by which space and time are linked within the brain (Edelman and Gally, 1992). With a half-life in the order of 1-5 s (Gally et al., 1990) and a diffusion constant $\left(2.6 \times 10^{-5} \mathrm{~cm}^{2} / \mathrm{s}\right)$ that is equivalent to passing through a $1 \mu \mathrm{m}^{2}$ area of membrane in the duration of an action potential $(0.5 \mathrm{~ms})$, it serves as a transient paracrine and autocrine signaling molecule. NO is produced in neurons in response to action potential-dependent release of glutamate whose post-synaptic sequestering facilitates the influx of $\mathrm{Ca}++$ ions through NMDA ( $N$-methyl-D-aspartate) receptors. NO is considered a major candidate as the retrograde messenger (post- to presynaptic direction) for long-term potentiation (LTP) associated with memory.

Even in the most elementary reactions NO (and CO, carbon monoxide) should be involved centrally with synaptic chemistry. With the copious presence of transient $\mathrm{COOH}$ (carboxyl) and $\mathrm{NH}_{3}$ (amine) groups from amino acid dynamics, $\mathrm{NH}_{3}+\mathrm{O}_{2}$ could yield a portion of $\mathrm{NO}+\mathrm{H}_{2} \mathrm{O}+\mathrm{H}+$ (a proton) and in more anaerobic environment $\mathrm{COOH}$ might yield a proportion of $\mathrm{CO}$ and $\mathrm{OH}-$ (a hydroxyl group) that when proximal to $\mathrm{H}+$ could maintain a buffering zone $\left(\mathrm{H}_{2} \mathrm{O}\right)$. NO reacting with $\mathrm{O}_{3}$ (ozone) results in light emission and the formation of nitrous dioxide $\left(\mathrm{NO}_{2}\right)$ and oxygen. The occurrence of biophotons or visible wavelengths (Popp, 1988) during action potentials (Bokkon, 2005; Dotta et al., 2011, 2012) is an emerging field of study with paradigm-shifting potential.

About 25\% of NO within the biosphere is formed by lightning discharges with absolute amounts of about $10 \mathrm{Tg} / \mathrm{yr}$ (range 2-100 Tg). The estimated numbers of $\mathrm{NO}_{x}$ molecules (NO plus other oxides) created by lightning energy is within the range of 1-26 × 10 ${ }^{16}$ molecules/J (Chang and Grossman, 1996). The production and distribution of NO significantly affects the level of ozone within the biosphere. More recent space-based measurements from optical transient detectors (Martin et al., 2007) indicated $44 \pm 5$ flashes per s globally with an estimated (medial value) of $5 \times 10^{25} \mathrm{~N}$ atoms/flash. Assuming $10^{9} \mathrm{~J} /$ stroke the numbers of atoms per J is between $10^{16}$ and $10^{17}$. Simulated lightning (Wang et al., 1998) produced $2 \times 10^{21} \mathrm{NO}$ molecules $/ \mathrm{m}$ per $5 \mathrm{~kJ} / \mathrm{m}$ of energy or about $10^{17} \mathrm{NO}$ per J. These measurements indicate the formation in the order of $10^{-2}$ to $10^{-3} \mathrm{NO}$ molecule per s per action potential equivalent of energy $\left(10^{-20} \mathrm{~J}\right.$, Persinger, 2010).

Within the brain NO is assumed to be produced from $\mathrm{L}$-arginine by isoforms of NO synthase as well as from non-enzymatic reactions associated with nitrite concentrations. The latter can increase 100 -fold with $\mathrm{pH}$ shifts (increased proton concentration) between 7.4 and 5.5 (Zweier et al., 1999). The synthesis of NO from addition of $100 \mu \mathrm{M}$ of L-arginine and NADPH ( $1 \mathrm{mM})$ to incubations containing synaptosomal cytosol induced synthesis of an average $40 \mathrm{pM} / \mathrm{min}$ per $\mathrm{cc}$, as determined by the product $\mathrm{NO}_{2}{ }^{-}$(Knowles et al., 1989). This is equivalent to $6 \times 10^{-13} \mathrm{M} / \mathrm{s} \cdot \mathrm{cc}$ or $\sim 3.6 \times 10^{11}$ 
molecules/s.cc. To simulate the volume of the dendritic spine of between 0.1 and $0.01 \mu \mathrm{m}^{3}\left(10^{-12} \mathrm{cc} / \mu \mathrm{m}^{3}\right)$ there would be $\sim 10^{-2}$ to $10^{-3} \mathrm{NO}$ molecules/s.

Employing Zweier et al.'s (1999) curves for non-enzymatic NO synthesis, $10 \mu \mathrm{M}$ of nitrite within a microenvironment of $\mathrm{pH}$ 3 yields $10^{-10} \mathrm{M} / \mathrm{s}$ of NO . The numbers of molecules of nitrite within a $0.1 \mu \mathrm{m}^{3}$ would be equivalent to $10^{-21} \mathrm{M}$ or $\sim 6 \times 10^{2}$ molecules/s. The proportion of NO formed from this concentration of nitrate would be between $10^{-2}$ and $10^{-3} / \mathrm{s}$. Consequently both lightning and the processes associated with membrane function generate comparable proportions of molecules of NO. This would suggest that the temporal-spatial integration (analogous to spatial and temporal summation for EPSPs and IPSPs) of action potential energies $\left(2 \times 10^{-20} \mathrm{~J}\right)$ from between 100 and $400 \mathrm{~Hz}$, the same range associated with optimal LTP, would be required to release a molecule of NO.

\section{NO AS INTRINSIC INFORMATION}

From the perspective of quantum theory, NO is a stable and unique radical. Even with its unpaired electron, the molecule displays no apparent paramagnetism. The magnetic susceptibility does not conform to the "spin-only" formula (Van Vleck, 1960; Kasai and Bishop, 1972) in one of its ground states due to the exact cancellation between the orbital magnetic moment and spin magnetic moment of the electron. This means NO is an example of a molecule that deviates from Curie's Law (the magnetic susceptibility of a paramagnetic material is proportional to the inverse of the absolute temperature) because the multiplets interval (the splitting of orbital energies) is comparable with the energy derived from the product of the Boltzmann constant and concurrent absolute temperature (the "kT" boundary). Hence the "information" contained within thermal noise within the synapse and the perisynaptic volume, when incorporated into the Boltzmann distribution, could be represented by NO within a magnetic field.

\section{THE ROLE OF THE PROTON}

The role of the proton $(\mathrm{H}+)$, in addition to its contribution to $\mathrm{pH}$ and the hydronium $\left(\mathrm{H}_{3} \mathrm{O}^{+}\right)$molecule, may be more extensive than suspected. Protons are unique ions with respect to the mechanism by which they traverse channels (DeCoursey, 2003). The proton is also unique among ions because it is interchangeable with the protons that form water. Both $\mathrm{K}+$ and $\mathrm{Na}+$ display several hydration states during the dynamics of channel movements. In physiological solutions, "free protons," although concentrated at about $40 \mathrm{nM}$, have a fivefold higher conductivity in water than other cations like $\mathrm{K}+$. Voltage-gated proton channels display both the largest and smallest single-channel currents.

Drift velocity is the square root of $\mathrm{J} / \mathrm{kg}$ (energy/mass). If we assume the $0.2 \mu \mathrm{V}$ change associated with a single-ion channel (Kandel etal., 2000), the energy exerted on a charge is $0.2 \times 10^{-6} \mathrm{~V} \times 1.6 \times 10^{-19} \mathrm{~A} \cdot \mathrm{s}$ or $0.5 \times 10^{-25} \mathrm{~J}$. When the square root of this value divided by the mass of a proton $\left(1.6 \times 10^{-27} \mathrm{~kg}\right)$ is obtained the velocity is about $4.5 \mathrm{~m} / \mathrm{s}$ which is remarkably congruent with the "bulk velocity" of the EM field that traverses the caudal-rostral plane of the cerebrum every $\sim 20 \mathrm{~ms}$. The $4.5 \mathrm{~m} / \mathrm{s}$ value divided by a typical human skull circumference of $6 \times 10^{-1} \mathrm{~m}(60 \mathrm{~cm})$ gives the value $7.5 \mathrm{~Hz}$.
With this value $(4.5 \mathrm{~m} / \mathrm{s})$ the time required for a proton to move through a membrane of $10 \mathrm{~nm}$ is $2.2 \times 10^{-9} \mathrm{~s}$. During the $1 \mathrm{~ms}$ associated with an action potential the number of protons moving through the membrane would be about 2.2 million. This number is remarkably similar in order of magnitude to the estimated number of cations that move through these $<1 \mathrm{~nm}$ width intramembrane conductive cylinders and to the numbers of ions that actually generate the resting plasma membrane potential (Persinger, 2010). When multiplied by the unit charge the net current could be within the $\mathrm{pA}\left(10^{-12} \mathrm{~A}\right)$ range, the typical order of magnitude for ion channels.

This congruence might suggest that the role of $\mathrm{Na}+$ in the action potential may be epiphenomenal because even the classical experiments that demonstrated "concentration-dependence" would have had concomitant changes in proton movements associated with hydration states. This concept has been elaborated by Del Giudice et al. (2010) and supported empirically by Gang et al. (2012). Interfacial water, contiguous to biological surfaces, remains static and generates exclusion zones that are about 10 -fold more viscous than normal water, contain a concentrations of protons, and exhibit negative potentials with respect to neighboring water of up to $150 \mathrm{mV}$.

\section{SHIFT IN PERSPECTIVE}

As a possible historical example, the conspicuous retrograde movements in Mars across the star canopy over successive nights was explained just as well by the epicycles superimposed upon the concentric orbits around the earth (the "geocentric" universe) described in the Almagest by Ptolemy Claudius of ancient Alexandria as by the heretical heliocentric models proposed by Copernicus and Kepler. Only detailed examination and finer temporal and spatial resolutions revealed the relevancy of the more precise mechanism.

As indicated, the scale-invariant similarities between lightening and action potentials evoke the possibility of mutual interaction. In addition to comparable values for magnetic and electric fields, the power density for Schumann resonances within the $8-21 \mathrm{~Hz}$ range is in the order of $10^{-10} \mathrm{~W} / \mathrm{m}^{2} / \mathrm{Hz}$ (Polk, 1982). This is the same order of magnitude as the power density of photon emissions from the human brain during imagination (Dotta etal., 2011) and the correlated changes in power measures from quantitative EEG (Dotta et al., 2012). Laboratory experiments by Schienle etal. (1997), who exposed volunteers for about $1 \mathrm{ks}$ to simulated lightening-related sferics by generating $10 \mathrm{kHz}$ signatures (amplitude $50 \mathrm{nT}$, pulse repetition: 7-20 Hz; pulse duration $0.5 \mathrm{~ms}$ ), demonstrated that protracted changes within the alpha band and experiences similar to those attributed to natural phenomena were reliably elicited.

The similarities in quantitative characteristics between action potentials and lightening presented in this paper might be expected if the intrinsic organizations of matter and energy are reflected within different spatial and temporal levels of observation (Persinger and Koren, 2007). Perhaps by careful quantification and observation of the larger phenomena, such as lightning, processes can be discerned that will point the direction of focus for what we have not yet measured. 


\section{REFERENCES}

Blinkov, S. M., and Glezer, I. I. (1968). The Human Brain in Figures and Tables. New York: Basic Books.

Bokkon, I. (2005). Dreams and neuroholography: an interdisciplinary interpretation of development of homeotherm state in evolution. Sleep Hypn. 7, 61-76.

Burkitt, G. R., Silberstein, R. B., Cadusch, P. J., and Wood, A. W. (2000). Steady-state visual evoke potentials and travelling waves. Clin. Neurophysiol. 111, 246-258.

Campbell, W. H. (1967). "Geomagnetic pulsations," in Physics of Geomagnetic Phenomena, eds S. Matsushita and W. H. Campbell (New York: Academic Press), 821-909.

Chang, B., and Grossman, A. S. (1996). $\mathrm{NO}_{x}$ Production from Lightning. Springfield, VA: US Department of Commerce.

Cherry, N. (2002). Schumann resonances, a plausible biophysical mechanism for the human health effects of solar/geomagnetic activity. Nat. Hazards 26, 279-331.

Clements, J. D. (1996). Transmitter timecourse in the synaptic cleft: its role in the central synaptic function. Trends Neurosci. 19, 163-171.

DeCoursey, T. E. (2003). Voltage-gated proton channels and other proton transfer pathways. Physiol. Rev. 83, 475-579.

Del Giudice, W., Spinetti, P. R., and Tedeschi, A. (2010). Water dynamics at the root of metamorphosis in living organisms. Water 2, 566-586.

Dotta, B. T., Buckner, C. A., Lafrenie, R. M., and Persinger, M. A. (2011). Photon emissions from human brain and cell culture exposed to distally rotating magnetic fields shared by separate light-stimulated brains and cells. Brain Res. 1388, 77-88.

Dotta, B. T., and Persinger, M. A. (2011). Increased photon emissions from the right but not the left hemisphere while imaging white light in the dark: the potential connection between consciousness and cerebral light. J. Cons. Explor. Res. 2, 1463-1473.

Dotta, B. T., Saroka, K. S., and Persinger, M. A. (2012). Increased photon emission from the head while imagining white light is correlated with changes in electroencephalographic power: support for Bokkon's biophoton hypothesis. Neurosci. Lett. 513, 151-154.

Durand-Manterola, H. J., Mendoza, B., and Diaz-Sandoval, R. (2001). Electric currents induced inside biological cells by geomagnetic and atmospheric phenomena. Adv. Space Res. 28, 679-684.
Edelman, G. M., and Gally, J. A. (1992). Nitric oxide: linking space and time in the brain. Proc. Natl. Acad. Sci. U.S.A. 89, 11651-11652.

Gally, J. A., Montague, P. R., Reeke, G. N., and Edelman, G. M. (1990). The NO hypothesis: possible effects of a short-lived rapidly diffusible signal in the development and function of the nervous system. Proc. Natl. Acad. Sci. U.S.A. 87, 3547-3551.

Gang, N., St-Pierre, L. S., and Persinger, M. A. (2012). Water dynamics following treatment by one hour 0.16 Tesla static magnetic fields depend on exposure volume. Water 3, 122-131.

Gazalé, M. J. (1999). Gnomon. Princeton, NJ: Princeton University Press.

Golding, N. L., Kath, W. L., and Spruston, N. (1999). Dichotomy of action-potential backpropagation in CA1 pyramidal neuron dendrites. $J$. Neurophysiol. 86, 2998-3010.

Houwelling, A. R., and Brecht, M (2008). Behavioural report of a single neuron in somatosensory cortex. Nature 461, 65-68.

Israel, H. (1973). Atmospheric Electricity: Vol. II: Fields, Charges, Currents. Springfield, VA: National Technical Information Service, US Department of Commerce.

Kandel, E. R., Schwartz, J. H., and Jessell, T. M. (2000). Principles of Neural Science, 4th Edn.. NY: McGraw-Hill.

Kasai, P. H., and Bishop, R. J. (1972). Electron spin resonance study of nitric oxide adsorption on Linde type zeolites. J. Amer. Chem. Soc. 94 5560-5566.

Knowles, R. G., Palacios, M., Palmer, R. M., and Moncada, S. (1989). Formation of nitric oxide from L-arginine in the central nervous system: a transduction mechanism for stimulation of soluble guanylate cyclase. Proc. Natl. Acad. Sci. U.S.A. 86, 5159-5162.

Koenig, H. L., Krueger, A. P., Lang, S., and Sönning, W. (1981). Biological Effects of Environmental Electromagnetism. New York: Springer-Verlag.

Koenig, T., Prichep, L., Lehamnn, D. Sosa, P. V., Braeker, E., Kleinlogel, H., Isenhart, R., and John, E. R. (2002). Millisecond by millisecond, year by year: normative EEG microstates and developmental stages. Neuroimage $16,41-48$.

Kolombet, V. A. (1996). Biological physics? Biophysics 40, 1137-1146.

Lehmann, D., Strik, W. K., Henggeler, B., Koenig, T., and Koukkou, M. (1998). Brain electric microstates and momentary conscious mind states as building blocks of spontaneous thinking: I. Visual imagery and abstract thoughts. Int. J. Psychophysiol. 29, 1-11.
Li, C. Y., Poo, M. M., and Day, Y. (2009). Burst-firing of a single cortical neuron modifies global brain state. Science 324, 643-646.

Llinas, R. R., and Pare, D. (1991). Of dreaming and wakefulness. Neuroscience 44, 521-535.

Llinas, R., and Ribary, U. (1993). Coherent $40-\mathrm{Hz}$ oscillation characterizes dream state in humans. Proc. Natl. Acad. Sci. U.S.A. 90, 2078-2081.

Martin, R. V., Sauvage, B., Folkins, I., Sioris, C. E., Boone, C., Bernath, P., and Zeimke, J. (2007). Spacebased constraints on the production of nitric oxide by lightning. J. Geophys. Res. 112, D09309 (1-14).

Mulligan, B. P., Hunter, M. D., and Persinger, M. A. (2010). Effects of geomagnetic activity and atmospheric power variations on quantitative measures of brain activity: replication of the Azerbaijani studies. Adv. Space Res. 45, 940-948.

Nunez, P. L. (1995). "Towards a physics of the neocortex," in Neocortical Dynamics And the Human EEG Rhythms, ed. P. L. Nunez (New York: Oxford), 68-131.

Ogawa, S. T. (1982). "The lightning current," in CRC Handbook of Atmospherics, Vol. 1, ed. H. Volland (Boca Raton: CRC Press), 23-63.

Persinger, M. A. (1999). On the nature of space-time in the observation of physical events in Science. Percept. Mot. Skills 88, 1210-1216.

Persinger, M. A. (2008). On the possible representation of the electromagnetic equivalents of all human memory within the earth's magnetic field: implications for theoretical biology. Theor. Biol. Insights 1, 3-11.

Persinger, M. A. (2010). $10^{-20}$ Joules as a neuromolecular quantum in medicinal chemistry: an alternative approach to myriad molecular pathways? Cur. Med. Chem. 17, 30943098.

Persinger, M. A. (2011). Electromagnetic bases of the universality of the characteristics of consciousness: quantitative support. J. Cosmol. 14 (in press).

Persinger, M. A., and Koren, S. A. (2007). A theory of neurophysics and quantum neuroscience: implications for brain function and the limits of consciousness. Int. J. Neurosci. 117, 157-175.

Persinger, M. A., Koren, S. A., and Lafreniere, G. F. (2008). A neuroquantologic approach to how human thought might affect the universe. NeuroQuantology 6, 262-271.

Persinger, M. A., and Lavallee, C. F. (2010). Theoretical and experimental evidence of macroscopic entanglement between human brain activity and photon emissions: implications for quantum consciousness and future applications. J. Cons. Explor. Res. 1, 785-807.

Persinger, M. A., and Lavallee, C. F. (2012). The $\Sigma \mathrm{N}=\mathrm{n}$ concept and the quantitative support for the cerebral-holographic and electromagnetic configuration of consciousness. J. Conscious. Study (in press).

Persinger, M. A., Ludwig, H. W., and Ossenkopp, K.-P. (1973). Psychophysiological effects of extremely low frequency electromagnetic fields: a review. Percept. Mot. Skills 36, 1131-1159.

Persinger, M. A., Meli, S., and Koren, S. A. (2008). Quantitative discrepancy in cerebral hemispheric temperature associated with "two consciousnesses" is predicted by neuroquantum relations. NeuroQuantology 6, 369-378.

Piccolino, M. (1997). Luigi Galvani and animal electricity: two centuries after the foundation of electrophysiology. Trends Neurosci. 20, 443-448.

Polk, C. (1982). "Schumann resonance," in CRC Handbook of Atmospherics, Vol. 1, ed. H. Volland (Boca Raton: CRC Press), 111-178.

Popp, F.-A., (1988). Biophoton emission. Experientia 44, 543-630.

Rai, J., and Bhattacharya, P. K. (1971). Impulse magnetic flux density close to the multiple return strokes of a lightning discharge. J. Phys. D. App. Phys. 4, 1252-1255.

Rennie, J. (1999). Scientific American: Science Desk Reference. New York: John Wiley \& Sons.

Schienle, A., Stark. R., and Vaitl, D. (1998). Biological effects of very low frequency (VLF) atmospherics in humans: a review. J. Sci. Explor. 12, 455-468.

Schienle, A., Stark, R., Walter, B., Kulzer, R., and Vaitl, D. (1997). Effects of low frequency magnetic fields on electrocortical activity in humans: a sferics simulation study. Int. J. Neurosci. 90 21-36.

Schlegel, K., and Fullekrug, M. (1999). Schumann resonance parameter changes during high-energy particle precipitation. J. Geophys. Res. 104, 111-118.

Tsang, E. W., Koren, S. A., and Persinger, M. A. (2004). Power increases within the gamma range over the frontal and occipital regions during acute exposures to cerebrally counterclockwise rotating magnetic fields with specific derivatives of change. Int. J. Neurosci. 114, 183-194.

Tu, L. C., Luo, J., and Gilles, G. T. (2005). The mass of the photon. Rep. Prog. Phys. 68, 77-130. 
Van Vleck, J. H. (1960). Fundamental Formulas of Physics, Vol. 2. New York: Dover, 633-640.

Villanueva, Y., Rakov, V. A., and Uma, M. A. (1994). Microsecond-scale electric field pulses in cloud lightning discharges. J. Geophys. Res. 99, 353-360.

Wang, Y., DeSilva, A. W., and Goldenbaum, G. C. (1998). Nitric oxide production by simulated lightning: dependence on current, energy, and pressure. J. Geophys. Res. 103, 19149-19159.
Wei, L. Y. (1969). Molecular mechanisms of nerve excitation and conduction. Bull. Math. Biophys. 31, 39-59.

Zhang, Q., Qie, X., Wang, Z., Zhang, T., Zhao, Y., Yang, J., and Kong, X. (2009). Characteristics and simulation of lightning current waveforms during one artificially triggered lightning. Atmos. Res. 91, 387-392.

Zweier, J. L., Samouilov, A., and Kuppusamy, P. (1999). Non-enzymatic nitric oxide synthesis in biological systems. Biochim. Biophys. Acta 1411, 250-262.

Conflict of Interest Statement: The author declares that the research was conducted in the absence of any commercial or financial relationships that could be construed as a potential conflict of interest.

Received: 18 November 2011; paper pending published: 27 December 2011 accepted: 24 April 2012; published online: 15 May 2012
Citation: Persinger MA (2012) Brain electromagnetic activity and lightning. potentially congruent scale-invariant quantitative properties. Front. Integr. Neurosci. 6:19. doi: 10.3389/fnint.2012. 00019

Copyright (C) 2012 Persinger. This is an open-access article distributed under the terms of the Creative Commons Attribution Non Commercial License, which permits non-commercial use, distribution, and reproduction in other forums, provided the original authors and source are credited. 